\title{
The effect of multiaxial stress state on formation of rafts in CMSX-4 superalloy during creep
}

\author{
Marek Gebura,a, Juraj Lapin ${ }^{1, b}$ \\ ${ }^{1}$ Institute of Materials and Machine Mechanics, Slovak Academy of Sciences, Račianska 75, \\ 83102 Bratislava, Slovakia \\ aummsgebu@savba.sk, bummslapi@savba.sk
}

Keywords: Superalloy. Creep. Multiaxial stress state. Microstructure degradation.

\begin{abstract}
The effect of multiaxial stress state caused by a notch effect on microstructure degradation of single crystal nickel based superalloy CMSX-4 was studied during creep at a temperature of 950 ${ }^{\circ} \mathrm{C}$, under constant nominal stress of $120 \mathrm{MPa}$ for 500 and $1000 \mathrm{~h}$. In order to minimize surface oxidation effects on microstructure degradation and notched geometry of specimens, all experiments were performed under protective atmosphere. The geometry of creep specimens was designed with the aim to obtain defined interval of principal stresses, which is sufficiently large to get reliable microstructure response during tensile creep experiments. Flat specimens with "U-type" notch were designed using elastic finite element method (FEM) calculations. Microstructure analysis of the crept specimens showed that notches affect degradation processes of the studied superalloy significantly. FEM elastic-plastic analysis was performed to simulate creep of the notched specimens. Material creep behaviour was integrated into calculations by a subroutine using equations derived from experimentally measured data for cylindrical creep specimens tested at various constant nominal stresses. Magnitude, distribution and orientation of principal stresses resulting from the specimen loading were calculated and their effect on formation of rafts was described.
\end{abstract}

\section{Introduction}

Nickel based superalloys are widely used in aircraft and power engineering due to their excellent properties at high temperatures such as creep and oxidation resistance. A typical microstructure of these alloys usually contains $\mathrm{L}_{2}$-ordered $\gamma^{\prime}\left(\mathrm{Ni}_{3}(\mathrm{Al}, \mathrm{Ti})\right)$ precipitates coherently embedded in $\gamma$ (Ni based solid solution with face-centered cubic crystal structure) matrix. The mechanical properties of nickel based superalloys depend on the volume fraction, distribution, size and morphology of $\gamma^{\prime}$ precipitates. At high temperatures, initial cuboidal $\gamma / \gamma^{\prime}$ microstructure undergoes first the process of Ostwald ripening [1,2] and consequently the process of formation of spontaneous rafts [3]. When external stress is applied in a direction parallel to [001] crystallographic direction, the cuboidal $\gamma^{\prime}$ precipitates undergo directional coarsening (rafting) with the rafts oriented in a direction perpendicular to the loading axis. Formation of creep rafts has been intensively studied and relatively well described by many authors, e.g. [4-6].

The first stage blades for industrial gas turbines or aircraft engines are often cooled with internal channels that act as notches during their service. However, there is lack of available data about the effect of multiaxial stress conditions caused by such notches on microstructure degradation of single crystal nickel based superalloys [7-9]. The aim of the present work is to study the effect of multiaxial stress conditions caused by a notch on microstructure degradation changes of single crystal nickel based superalloy CMSX-4.

\section{Experimental procedures}

The alloy CMSX-4 with the chemical composition Ni-7.0Cr-9.0Co-0.6Mo-6.0W-7.0Ta-3.0Re5.6Al-1.0Ti-0.1Hf (wt.\%) was provided by ALSTOM Ltd. in the form of cylindrical heat treated single crystal bars with a diameter of $20 \mathrm{~mm}$ and a length of $190 \mathrm{~mm}$. The bars were cut to smaller pieces using spark machining and then grinded to rectangular cuboids with dimensions of $6 \times 15 \times 80$ 
mm. FEM calculations were performed to design geometry of a flat creep specimens for the study of the effect of multiaxial stress conditions on microstructure degradation of single crystal nickel based superalloy during creep. Geometry of a flat creep specimen was designed with "U-type" of notch characterized by radius of $1.5 \mathrm{~mm}$. Threaded heads of the creep specimens were lathe machined. Final geometry with defined dimensions was then achieved by precise grinding. Fig. 1 shows a notched CMSX-4 specimen before creep testing. Assuming service conditions of single crystal turbine blades, creep experiments were performed at $950{ }^{\circ} \mathrm{C}$ under constant nominal tensile stress of $120 \mathrm{MPa}$ for 500 and $1000 \mathrm{~h}$. In order to minimize surface oxidation, a special apparatus enabling creep under flow of a protective atmosphere (Ar or He) was used.

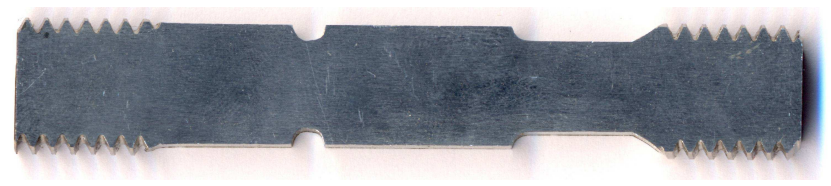

Fig. 1. Creep specimen with "U-type" of notch.

Microstructural analysis was performed by light optical microscopy (OM) and scanning electron microscopy (SEM). Samples for OM and SEM were prepared using standard metallographic techniques. However, they were grinded more to depth before microstructural analysis in order to avoid unfavorable effects of their geometry on stress state and microstructure degradation during creep in their top side. Optimal depth of $1.2 \mathrm{~mm}$ was determined from distribution of principal stresses calculated by FEM elastic analysis. Consequently they were etched in a reagent containing $12.5 \mathrm{ml}$ alcohol, $12.5 \mathrm{ml} \mathrm{HNO}_{3}$ and $13.5 \mathrm{ml} \mathrm{HCl}$.

In order to simulate creep within the notched specimens, FEM elastic-plastic analysis was performed. Magnitude, distribution and orientation of stresses resulting from the specimen loading were calculated using mesh with 3D 20-node quadratic elements. Creep behavior of CMSX-4, necessary for FEM simulation, was integrated by user-defined subroutine using equation based on experimentally measured creep data of cylindrical specimens without notch tested at constant nominal stresses of 90,120 and $150 \mathrm{MPa}$ [11]. Stress relaxation during creep was taken into account for FEM calculations.

\section{Results and discussion}

Initial microstructure within the creep specimens consists of cuboidal shaped $\gamma^{\prime}$ precipitates embedded in the $\gamma$ matrix (Fig. 2a). Mean precipitate size and average volume fraction of the $\gamma^{\prime}$ precipitates was measured to be $310 \pm 6 \mathrm{~nm}$ and $69.5 \pm 1 \mathrm{vol} . \%$, respectively. This is in agreement with previous measurements made by Lapin et al. [1].

Using SEM, three different regions of $\gamma / \gamma^{\prime}$ microstructure in the vicinity of notch after $1000 \mathrm{~h}$ of creep at constant nominal stress of $120 \mathrm{MPa}$ at $950{ }^{\circ} \mathrm{C}$ were found: (i) region with only cuboidal $\gamma^{\prime}$ precipitates (region A), (ii) region with non-uniformly rafted $\gamma^{\prime}$ precipitates (region B) and (iii) region with uniformly rafted $\gamma^{\prime}$ (region $\mathrm{C}$ ). Figs. $2 \mathrm{~b}$ and $2 \mathrm{c}$ show microstructures related to region with non-uniformly and uniformly rafted $\gamma^{\prime}$ precipitates, respectively.

In order to simulate the effect of creep on geometry of flat specimens, elastic-plastic FEM analysis was performed. Creep equation based on time-strain creep deformation curves measured independently on cylindrical specimens without any notches at constant external nominal stresses $\sigma_{\text {ext }}$ of 90,120 and $150 \mathrm{MPa}$ was determined and consequently used for user-subroutine preprogramming. A negligible amount of strain was assigned to the lowest possible stress of $1 \mathrm{MPa}$ within the loaded specimen (based on the FEM elastic analysis) to avoid negative values of calculated strain for low stresses. General form of this fourth grade polynomial equation is as follows: 


$$
\varepsilon_{\text {calc }}=a+b t+c t^{2}+d t^{3}+e t^{0.5}
$$

where $\varepsilon_{\text {calc }}$ represents calculated strain, $t$ is time and $a, b, c, d$ and $e$ are numerical constants, whereas all are functions of $\sigma_{\text {ext }}$.

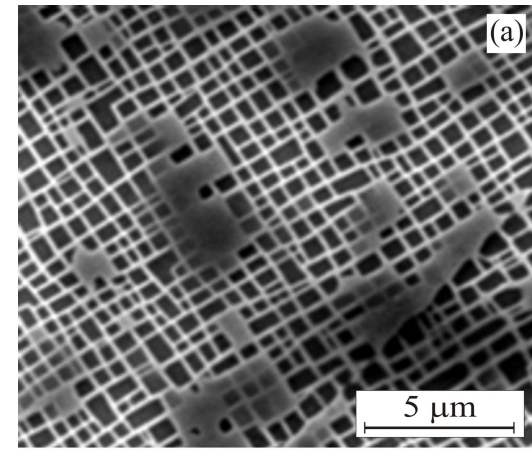

Fig. 2. (a) Initial microstructure, microstructure within region $\mathrm{C}$.
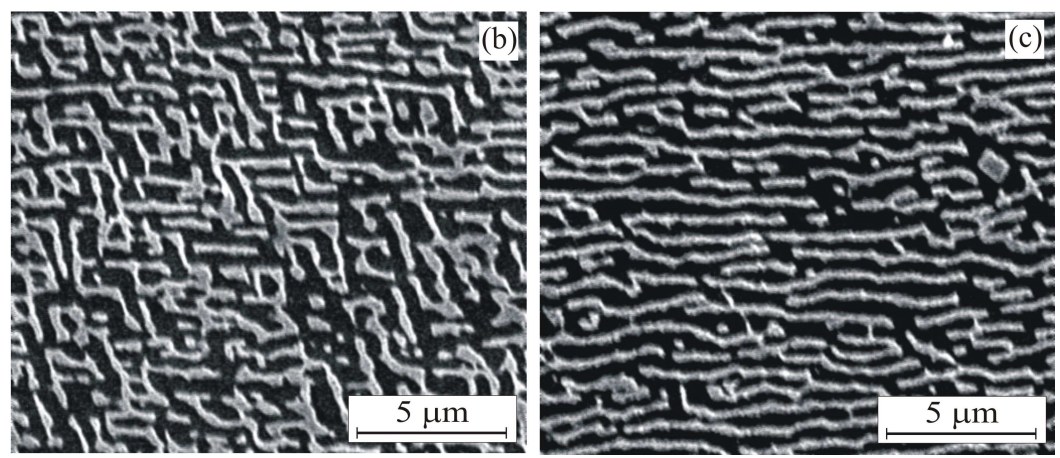

After derivation of Eq. (1), one can get formula for the calculated strain rate $\dot{\varepsilon}_{\text {calc }}$ :

$$
\dot{\varepsilon}_{\text {calc }}=b_{r}+c_{r} t+d_{r} t^{2}+\frac{e_{r} t^{-0.5}}{2}
$$

where $b_{\mathrm{r}}, c_{\mathrm{r}}, d_{\mathrm{r}}$ and $e_{\mathrm{r}}$ represent numerical constants. Eq. (1) allows calculating creep strains at a temperature of $950{ }^{\circ} \mathrm{C}$ and maximal external nominal stress of $200 \mathrm{MPa}$ applied for up to $2000 \mathrm{~h}$. Fig. 3 shows comparison between the experimentally measured (symbols) and calculated values (dashed lines) of strain for constant nominal external stresses of 90, 120 and $150 \mathrm{MPa}$ during creep at $950{ }^{\circ} \mathrm{C}$ up to $2000 \mathrm{~h}$. Eq. (1) was verified by comparing strain-strain rate of calculated values (using Eq. (2)) and experimentally measured ones. It is clear that both, time-strain and strain-strain rate behaviors based on Eqs. (1) and (2) are in very good agreement with those measured experimentally.

Fig. 4 shows the sketch of "U-type" notch, where dashed line with length $l$ represents the path for further examination of stress state and related microstructure. Initial and final points for analysis are depicted as I and II, respectively.
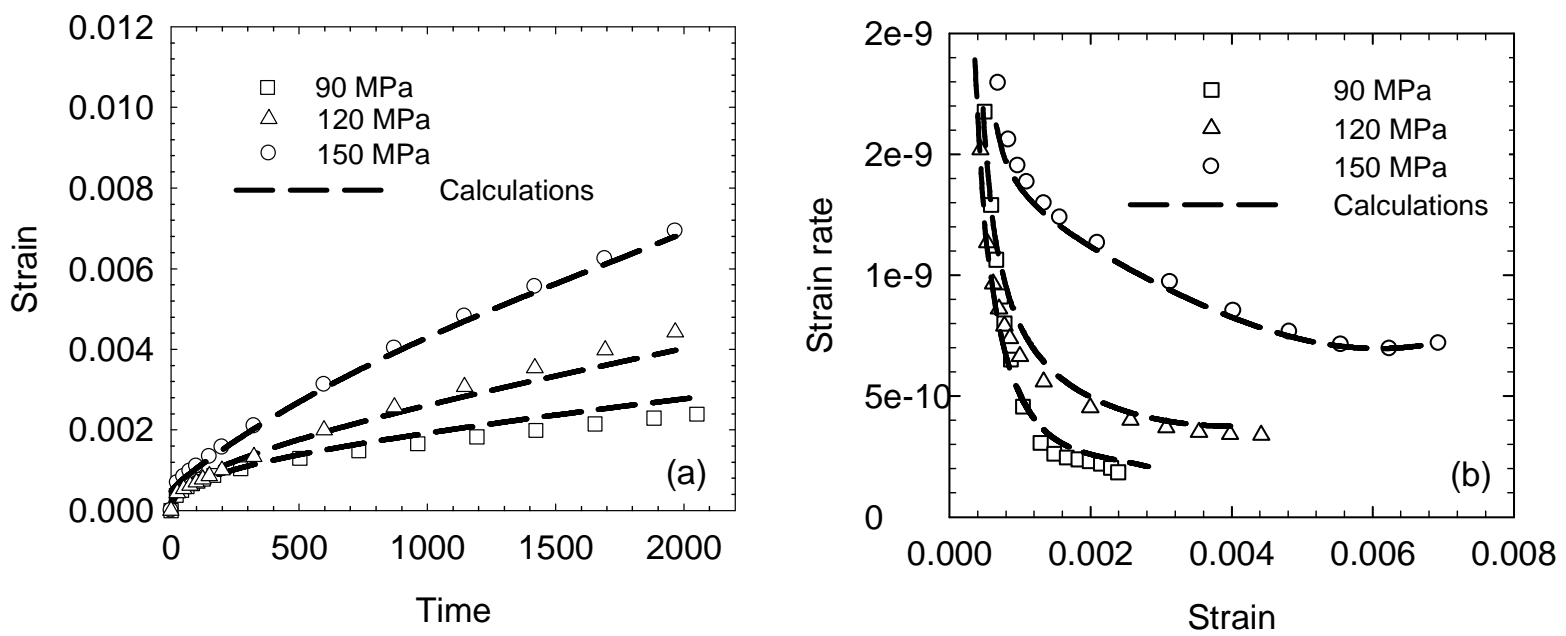

Fig. 3. Comparison between the experimentally measured (symbols) and calculated values (dashed lines) for constant nominal external stresses of 90,120 and $150 \mathrm{MPa}$ during creep at $950{ }^{\circ} \mathrm{C}$ for $2000 \mathrm{~h}$ : (a) dependence strain on time and (b) dependence of strain rate on strain. 


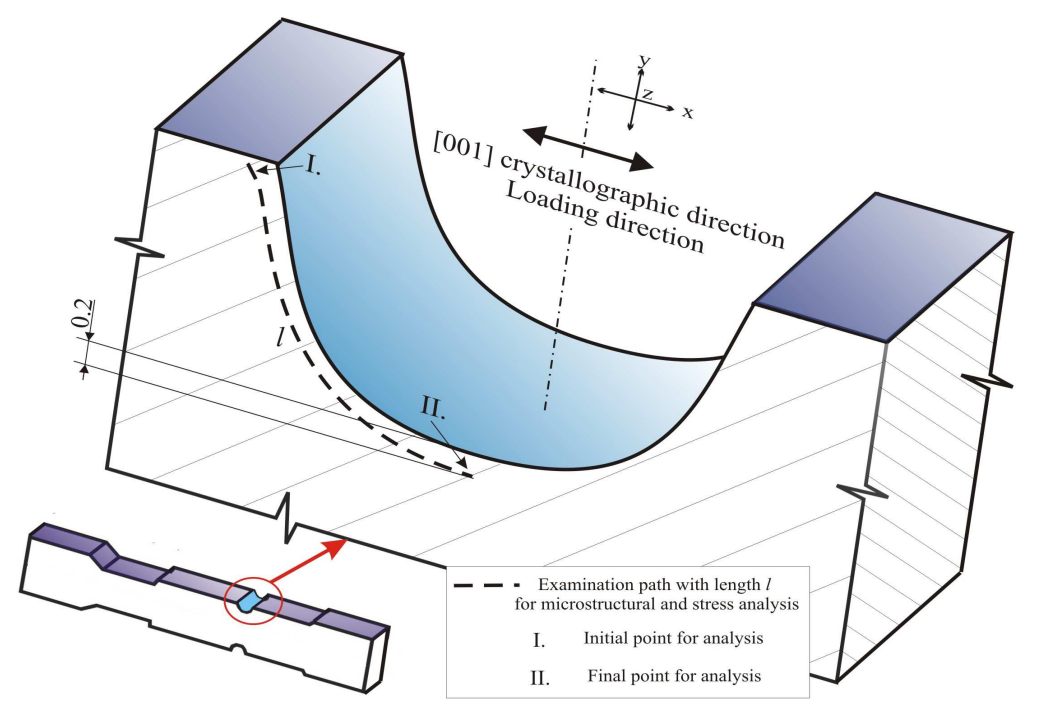

Fig. 4. Sketch of "U-type" of notch with dashed line representing the path for further examination of stress distribution and microstructure. xy-plane represents (001) crystallographic plane. Specimens were grinded into depth of $1.2 \mathrm{~mm}$ before microstructural analysis was performed.

One of the possibilities to define stress state is to define three principal stresses $\sigma_{1}, \sigma_{2}, \sigma_{3}$, whereas following can be considered for a given point in space:

$$
\begin{aligned}
& \sigma_{\text {max }}=\max \left(\sigma_{1}, \sigma_{2}, \sigma_{3}\right) \\
& \sigma_{\text {min }}=\min \left(\sigma_{1}, \sigma_{2}, \sigma_{3}\right) \\
& \sigma_{\text {mid }}=\left(\sigma_{1}+\sigma_{2}+\sigma_{3}\right)-\sigma_{\text {max }}-\sigma_{\text {min }}
\end{aligned}
$$

where $\sigma_{\max }$ represents the highest tensile stress, $\sigma_{\min }$ the highest compressive stress (if there is no compressive stress, it represents the lowest value of tensile stress) and $\sigma_{\text {mid }}$ is so called stress intensity. In order to define distribution of stresses within the notched specimens before creep, FEM elastic analysis was performed and Von Mises stress $\sigma_{\mathrm{VM}}$ defined as

$$
\sigma_{V M}=\sqrt{\sigma_{1}^{2}+\sigma_{2}^{2}+\sigma_{3}^{2}-\sigma_{1} \sigma_{2}-\sigma_{2} \sigma_{3}-\sigma_{3} \sigma_{1}}
$$

was calculated. Distribution of $\sigma_{\mathrm{VM}}$ in the vicinity of the notch before creep is shown in Fig. 5a. During creep stresses in notched specimens are known to redistribute [10]. Fig. 5b shows the behavior of calculated stresses $\sigma_{\max }, \sigma_{\min }$ and $\sigma_{\text {mid }}$ after $1000 \mathrm{~h}$ of creep along the length $l$ of examined path from an initial point I to point II (please refer to Fig. 4), respectively. This figure also shows the behavior of angle $\varphi$ that represents an angle between direction of calculated $\sigma_{\max }$ and main $\mathrm{x}$-axis clockwise in $\mathrm{xy}$-plane. Diagram in this figure is attributed to the regions $\mathrm{A}, \mathrm{B}$ and $\mathrm{C}$ which were introduced earlier.
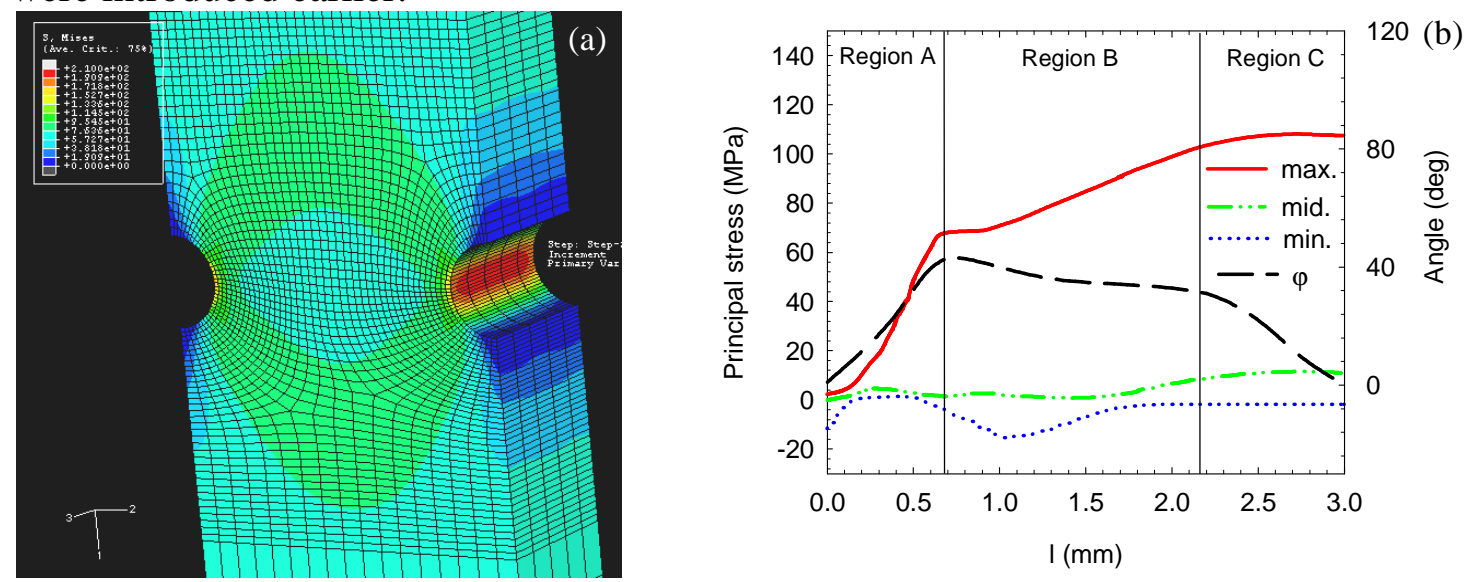

Fig. 5. a) Distribution of Von Mises stress in the vicinity of notch before creep. b) Behavior of calculated principal stresses $\sigma_{\max }, \sigma_{\min }, \sigma_{\operatorname{mid}}$ and angle $\varphi$ along examined path (see Fig. 4) after $1000 \mathrm{~h}$ of creep. 
As was shown earlier by Kamaraj et al. [8] and Serin et al. [9], rafting of $\gamma^{\prime}$ precipitates during high temperature low stress creep of single crystal superalloys depends on the stress state and stress level. After $1000 \mathrm{~h}$ of creep, there is no significant degradation of cuboidal $\gamma / \gamma^{\prime}$ microstructure within the region A. This region lies in the vicinity of examined path up to $0.68 \mathrm{~mm}$ from the point I. Based on microstructural analysis and taking into account calculated values of $\sigma_{\max }, \sigma_{\min }, \sigma_{\operatorname{mid}}$ and $\varphi$, one can say that even after $1000 \mathrm{~h}$ of creep at $950{ }^{\circ} \mathrm{C}$, the magnitude of $\sigma_{\max }$ is not sufficient to promote rafting. Microstructure remains cuboidal and coarsening known also as Ostwald ripening of the $\gamma^{\prime}$ precipitates takes place predominantly. This is in agreement with earlier quantitative measurements made by Lapin et al. [11] performed on cylindrical creep specimens with multiple gauge sections at four constant nominal external stresses of $60,90,120$ and $150 \mathrm{MPa}$ at a temperature of $950{ }^{\circ} \mathrm{C}$.

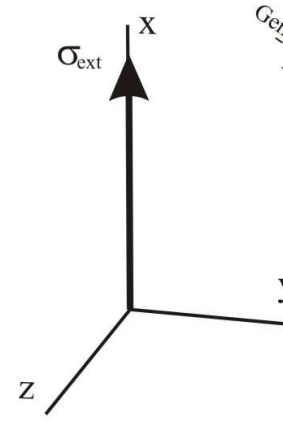

(a)

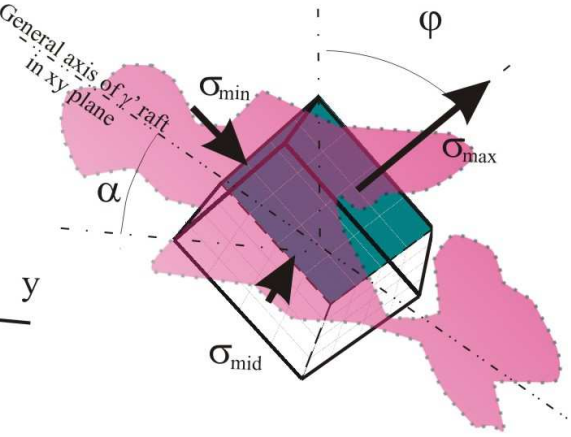

(b)

Fig. 6. Stress state at point $X$ of the examined path. a) Main Cartesian coordinate system with direction of external load $\sigma_{\text {ext. }}$ b) Elementary stress state cube representing the effect of principal stresses $\sigma_{\max }, \sigma_{\min }$ and $\sigma_{\text {mid }}$ on orientation of $\gamma^{\prime}$ phase after $1000 \mathrm{~h}$ of creep. Filled plane in elementary stress state cube represents plane parallel to xy-plane.

Before analyzing region $\mathrm{B}$, region $\mathrm{C}$ will be discussed because of less complicated stress state in comparison to region B. After $1000 \mathrm{~h}$ of creep, fully rafted $\gamma / \gamma^{\prime}$ microstructure was observed within this region, whereas predominant orientation of $\gamma^{\prime}$ rafts was found to be perpendicular to an external loading axis. There is no significant change in magnitudes of principal stresses in this region. The only change that can affect evolution of directional coarsening of the $\gamma^{\prime}$ phase is therefore the change in angle $\varphi$, which continuously increases from the point II to the end of region $\mathrm{C}$ from $\varphi=0$ to about $\varphi=50^{\circ}$. Accordingly to known fundamentals of rafting process [4], directional coarsening of the $\gamma$ ' phase occurs in a direction perpendicular to the applied load in superalloys with negative misfit values (the case of the studied CMSX-4). However, this agrees only for close vicinity of the point II at examined path through investigated notch. Even orientation of $\sigma_{\max }$ with $\varphi=50^{\circ}$ is insufficient to promote changes in predominant orientation of general axis of rafts within region $\mathrm{C}$.

Fig. 6 shows stress state at point $X\left(\sigma_{\max }=72 \mathrm{MPa}, \sigma_{\operatorname{mid}}=1 \mathrm{MPa}, \sigma_{\min }=-16 \mathrm{MPa}, \varphi=50^{\circ}, l=\right.$ $1.1 \mathrm{~mm}$ ) placed within the region B. In this figure, stress state is related to observed morphology of the $\gamma^{\prime}$ phase. Here, the formation of rafts is affected primarily by $\sigma_{\max }$ which has the highest magnitude from all principal stresses, but there is also a contribution from $\sigma_{\min }$ that cannot be neglected. Moreover, $\sigma_{\min }$ has compressive character and hence a tendency to orientate directional coarsening of $\gamma^{\prime}$ phase parallel to the direction of $\sigma_{\min }$. This kind of stress state seconded by high angular dimension of $\varphi$ results in $\gamma^{\prime}$ rafts with several protrusions in directions parallel and perpendicular to the external loading axis. This is in agreement with previous work made by Kamaraj et al. [8] on shear specimens of CMSX-6 superalloy (where $\sigma_{\max }=-\sigma_{\min }$ and $\sigma_{\operatorname{mid}}=0$ ). According to their findings the $\gamma$ ' rafts grow perpendicular to a tensile stress component and parallel to compressive stress components. In contrast to region $\mathrm{C}$, high angular dimension of $\varphi$ plays a role in general orientation of the $\gamma^{\prime}$ raft. This can be characterized by defining an angle $\alpha$ that represents the angle between the general axis of $\gamma^{\prime}$ raft in xy-plane and main $y$-axis. At the point $X, \alpha$ values approximately $40^{\circ}$, as can be seen from the sketch in Fig. 6. 


\section{Conclusions}

The investigation of the effect of multiaxial stress conditions caused by a notch effect on microstructure degradation of nickel base single crystal superalloy CMSX-4 during creep at $950{ }^{\circ} \mathrm{C}$ for 500 and $1000 \mathrm{~h}$ under an applied stress of $120 \mathrm{MPa}$ suggests following conclusions:

1. There is no evidence of directional coarsening of the cuboidal $\gamma / \gamma^{\prime}$ microstructure within the region affected by maximal principal stress values up to $60 \mathrm{MPa}$, even if there is a high magnitude of $\varphi$. Microstructure remains cuboidal, whereas the process of coarsening of the cuboidal $\gamma^{\prime}$ precipitates known as Ostwald ripening takes place within this region predominantly.

2. Fully rafted $\gamma / \gamma^{\prime}$ microstructure with the rafts oriented perpendicularly to the [001] crystallographic direction were observed within the region affected primarily by $\sigma_{\max }$, where $\sigma_{\text {mid }}$ and $\sigma_{\min }$ have negligible magnitudes. Even at $\sigma_{\max }$ with high angular magnitude of $\varphi$, the main axis of directionally coarsened $\gamma^{\prime}$ phase remains perpendicular to the [001] crystallographic direction, what is in contrast to the known theories of rafting.

3. Non-uniform directional coarsening of the $\gamma^{\prime}$ phase was observed within the region, where beside the effect of $\sigma_{\max }$, the effect of non-negligible $\sigma_{\min }$ with compressive character should be also taken into account. This kind of stress state seconded by high magnitude of $\varphi$ results in a directional coarsening of the $\gamma^{\prime}$ phase with several protrusions in directions parallel and perpendicular to the [001] crystallographic direction. Moreover, in contrast to the region where only $\sigma_{\max }$ was affecting degradation of microstructure, high values of $\varphi$ affects orientation of the $\gamma$ rafts.

\section{Acknowledgements}

This work was financially supported by the Slovak Grant Agency for Science under the contract VEGA 2/0157/10. Authors want to thank Dr. A. Scholz, Dr. A. Simon and Dipl.-Ing. M. Lyschik from Technical university of Darmstadt for their help in FEM creep calculations and to Dr. M. Nazmy for providing experimental material.

\section{References}

[1] J. Lapin, M. Gebura, T. Pelachová, M. Nazmy: Kovove Mater., Vol. 46 (2008), p. 313

[2] A. Baldan: J. Mater. Sci., Vol. 37 (2002), p. 2379

[3] M. Gebura, J. Lapin: Morphological changes of $\gamma$ in Ni-based superalloy during long-term ageing, In: 17th Int. Conference Metal 2008. Hradec nad Moravicí [CD ROM]. Ostrava: Tanger, (2008)

[4] F.R.N. Nabarro: Metall Mater. Trans A., Vol. 27 (1996), p. 513

[5] A. Ma, D. Dye, R.C. Reed: Acta Mater., Vol. 56 (2008), p. 1657

[6] R.C. Reed, N. Matan, D.C. Cox, M.A. Rist, C.M.F. Rae: Acta Mater., Vol. 47 (1999), p. 3367

[7] M. Gebura, J. Lapin, B Taraba: Microstructure degradation in notched nickel base single crystal superalloy CMSX-4 during creep, In: The $14^{\text {th }}$ International of PhD students' seminar Semdok 2009. Proceedings, Edited by EDIS, Žilina, p. 17, (2009)

[8] M. Kamaraj, C. Mayr, M. Kolbe, G. Eggeler: Scripta Mat., Vol. 38 (1998), p. 589

[9] K. Serin, G. Göbenli, G. Eggeler: Mat. Sci. Eng. A, Vol. 387 (2004), p. 133

[10] G. Eggeler, C. Wiesner: J. Strain Analysis for Engineering Design, Vol. 28 (1993), p. 13.

[11] J. Lapin, M. Gebura: unpublished results of creep of CMSX-4 superalloy. 